\title{
DETECÇÃO DA EXPANSÃO DA ÁREA MINERADA NO QUADRILÁTERO FERRÍFERO, MINAS GERAIS, NO PERÍODO DE 1985 A 2011 ATRAVÉS DE TÉCNICAS DE SENSORIAMENTO REMOTO
}

Detection of mining area expansion in the Ferriferous Quadrangle, Minas Gerais, from 1985 to 2011 by means of remote sensing techniques

\author{
JULIANA MARIA FERREIRA DE SOUZA DINIZ \\ ALINY APARECIDA DOS REIS \\ FAUSTO WEIMAR ACERBI JUNIOR \\ LUCAS REZENDE GOMIDE \\ Universidade Federal de Lavras \\ Departamento de Ciências Florestais - C.P. 3037 \\ CEP 37200-000 - Lavras - MG - Brasil
}

juju-dinizsvm@hotmail.com; alinyreis@hotmail.com; fausto@dcf.ufla.br;

lucasgomide@dcf.ufla.br

\begin{abstract}
RESUMO
O objetivo deste estudo foi analisar a evolução da área minerada no Quadrilátero Ferrífero $(\mathrm{QF})$, Minas Gerais, e quantificar a área coberta com vegetação florestal nativa que foi suprimida por esta atividade durante os últimos 26 anos. Foram utilizadas imagens TM/Landsat 5 correspondente a área de estudo nos anos de 1985, 1989, 2000 e 2011. Para cada ano de análise, utilizando técnicas de interpretação visual de imagens, foram criados polígonos identificando e delimitando as áreas mineradas. Para a análise da supressão da vegetação florestal nativa pela mineração, as imagens de 1985 foram classificadas gerando um mapa temático de uso e cobertura do solo do QF. Em seguida, os polígonos de mineração identificados em cada ano de análise foram sobrepostos ao mapa da vegetação nativa possibilitando o cálculo da área de vegetação florestal nativa suprimida pela expansão da mineração. Entre os anos de 1985 a 2011, observou-se aumento de $213 \%$ na área minerada no QF. As áreas suprimidas de vegetação florestal nativa entre os anos de 1985 a 1989,
\end{abstract}


1989 a 2000 e 2000 a 2011 corresponderam respectivamente a 324,42 ha, 948,98 ha e 1989,68 ha, com uma perda total de vegetação nativa de 3.263,07 ha.

Palavras-chave: Áreas Mineradas; Desmatamento; Sensoriamento Remoto.

\section{ABSTRACT}

This study aimed at analyzing the evolution of the mined area in the Quadrilatero Ferrífero (QF) region, Minas Gerais state, Brazil, as well as to quantify the area covered by native forest that has been removed by mining activities during the last 26 years. TM/Landsat5 images from 1985, 1989, 2000 and 2011 were used. For each year of analysis, polygons of mined areas were detected and delimited using visual image interpretation techniques. For the analysis of the area covered by native forest suppressed by mining activities, a land cover and land use map of the QF region was provided, by using images from 1985. Native forest areas suppressed by mining expansion were calculated overlaying the thematic map and the mining polygons for each year of analysis. Taking into account the period from 1985 to 2011 there was an increase of $213 \%$ in the mined area. The areas of native forest removed throughout the years 1985-1989, 1989-2000 and 2000-2011 were respectively equal to 324.42 ha, 948.98 ha and $1,989.68$ ha, with a total loss of 3,263.07 ha.

Keywords: Mined Areas; Deforestation; Remote Sensing

\section{INTRODUÇÃO}

O Quadrilátero Ferrífero (QF) foi ocupado pelos portugueses durante o ciclo do ouro, no século XVIII, e proporcionou o avanço da urbanização pelo estado de Minas Gerais (LAMOUNIER et al., 2011). Com a decadência da exploração do ouro, a exploração do minério de ferro tornou-se alternativa para as mineradoras mineiras, sendo atualmente responsável por aproximadamente $70 \%$ da produção nacional do minério de ferro (DNPM, 2010).

$\mathrm{O}$ QF é um ambiente único no estado, coberto por campos rupestres hematíticos, conhecidos como cangas, que representam um dos ecossistemas mais ameaçados do Brasil devido a sua distribuição restrita e principalmente à sua relação com a atividade mineradora (JACOBI \& CARMO, 2008). Além de ser uma região que abriga espécies endêmicas e ameaçadas de extinção, sendo considerado um ambiente prioritário para a conservação ambiental (DRUMMOND et al., 2005; LAMOUNIER et al., 2011; PIACENTINI et al., 2007).

Com área de aproximadamente $7.000 \mathrm{Km}^{2}$, na porção central do estado de Minas Gerais, o QF estende-se de Ouro Preto à Belo Horizonte e ostenta grandes riquezas minerais, como ouro, manganês e ferro, tornando-se uma região geologicamente importante do período Pré-Cambriano (RUCHKYS, 2009). O QF pode ser subdividido de acordo com a sua litoestratigrafia em quatro grupos, sendo eles: o Embasamento Cristalino, o Super grupo Rio das Velhas, o Super grupo Minas e o Grupo Itacolomi (ROESER \& ROESER, 2010). 
O setor mineral é responsável por inúmeros investimentos no Brasil, e em Minas Gerais este setor teve papel fundamental no avanço econômico do estado. Segundo Farias (2002) a mineração representa um dos setores básicos da economia nacional, podendo contribuir com a melhoria do bem estar e da qualidade de vida da população quando mantêm níveis de proteção ecológica e padrões de qualidade, além de programas que minimizem os impactos ambientais causados por esta prática.

Devido às grandes explorações que ocorreram ao longo dos anos, a região do QF sofreu inúmeras modificações relacionadas ao seus meios físico e biótico, além dos principais problemas oriundos da mineração, como a poluição do ar, da água e sonora, subsidência do terreno, e dispersão de metais pesados para o meio ambiente (FARIAS, 2002).

Os danos causados pela exploração mineral no QF se intensificaram com o decorrer dos anos, transformando e prejudicando cada vez mais o meio ambiente. Isso, não apenas nas áreas mineradas, mas também nas áreas vizinhas, sendo necessária a implantação de programas que monitorem e quantifiquem a área alterada e degradada pela mineração, e visem minimizar os impactos ambientais e socioeconômicos causados por esta atividade no meio ambiente e nas comunidades ao qual estão envolvidas.

Nesse sentido, o objetivo deste trabalho foi analisar a evolução da área minerada no QF, localizado na região centro-sudeste de Minas Gerais, através do uso de imagens do sensor TM/Landsat 5 no período de 1985 a 2011, e quantificar a área coberta com vegetação florestal nativa que foi suprimida por esta atividade durante esse período de tempo.

\section{MATERIAL E MÉTODOS}

\section{1 Área de Estudo}

A área de estudo compreende o Quadrilátero Ferrífero, localizado na região centro-sudeste de Minas Gerais, e contempla os municípios de Barão de Cocais, Bela Vista de Minas, Belo Horizonte, Belo Vale, Betim, Brumadinho, Caeté, Catas Altas, Congonhas, Conselheiro Lafaiete, Ibirité, Igarapé, Itabira, Itabirito, Itatiaiuçu, Itaúna, Jeceaba, João Monlevade, Mariana, Mário Campos, Mateus Leme, Moeda, Nova Lima, Ouro Branco, Ouro Preto, Piranga, Raposos, Ribeirão das Neves, Rio Acima, Rio Manso, Rio Piracicaba, Sabará, Santa Bárbara, Santa Luzia, São Brás do Suaçuí, São Gonçalo do Rio Abaixo, São Joaquim das Bicas, Sarzedo (Figura 1).

De uma forma mais precisa sua área tem como limites os vértices: a nordeste, a cidade de Itabira, a noroeste de Itaúna, a sudeste Mariana e a sudoeste a cidade de Congonhas. Seu limite pelas serras se dá ao norte pela Serra do Curral, a leste pela Serra do Caraça e pela ponta sul da Serra do Espinhaço, à oeste pela Serra da Moeda e à sul pela Serra de Ouro Branco. A região apresenta clima do tipo Cwa, segundo a classificação climática de Köeppen, tropical semiúmido, com duas estações climáticas bem definidas, inverno seco, com temperaturas inferiores a $18^{\circ} \mathrm{C}$ e verão 
úmido, apresentando temperaturas superiores a $22^{\circ} \mathrm{C}$ (VARAJÃO, 2009; GARCIA, 2007), apresentando alta incidência de raios ultravioleta, baixa umidade relativa do ar e presença de ventos (JACOBI et al., 2007; GARCIA, 2007). Outra característica ambiental desta área é o seu intenso aquecimento durante o dia e o seu resfriamento à noite (VICENT et al., 2002).

Figura 1 - Localização geográfica do Quadrilátero Ferrífero, MG.

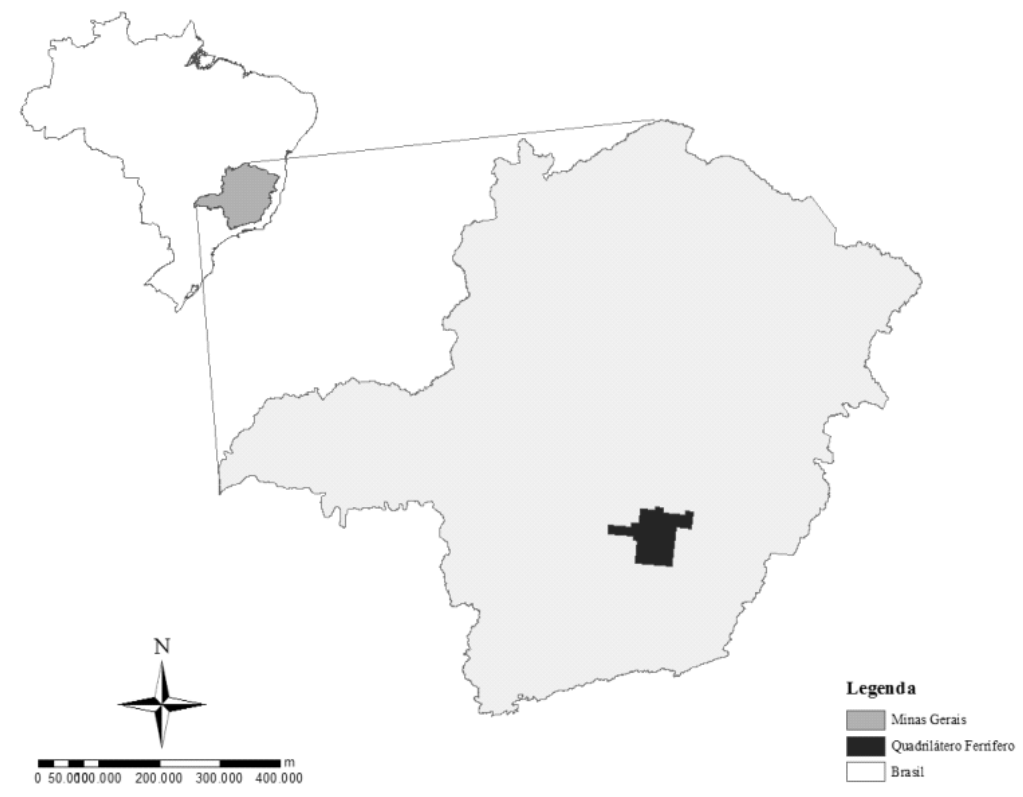

Diversas fitofisionomias ocorrem no QF tais como a floresta estacional semidecidual, as matas de galeria, os campos de altitude, o campo sujo, o campo cerrado e os campos rupestres (BRANDÃO et al., 1991; MEYER et al., 2004; SPÓSITO \& STEHMANN, 2006; VIANA \& LOMBARDI, 2007; JACOBI \& CARMO, 2008; VINCENT \& MEGURO, 2008). Sua vegetação predominante são os campos rupestres, um dos tipos fitofisionômicos do cerrado, caracterizado por estar presente em altitudes acima de 900 metros, sendo conhecido por vegetação de canga por estar associado aos afloramentos ferruginosos (GARCIA, 2007; CARMO, 2010).

\subsection{Série Temporal de Imagens}

Foram utilizadas imagens do sensor TM/Landsat 5 (Thematic Mapper) correspondentes a área de estudo dos anos de 1985, 1989, 2000 e 2011, perfazendo um período de análise de 26 anos. 
Para cada ano de análise foram necessárias duas cenas para compor um mosaico correspondente à área de estudo. Na Tabela 1 encontra-se o detalhamento das imagens utilizadas neste estudo.

Tabela 1 - Imagens utilizadas neste estudo.

\begin{tabular}{c|c|c|c}
\hline Satélite & Sensor & Cena & Data \\
\hline \multirow{4}{*}{ Landsat 5 } & TM & $217-074$ & $04 / 07 / 1985$ \\
\cline { 2 - 4 } & TM & $218-074$ & $15 / 10 / 1985$ \\
\cline { 2 - 4 } & TM & $217-074$ & $15 / 07 / 1989$ \\
\cline { 2 - 4 } & TM & $218-074$ & $22 / 07 / 1989$ \\
\cline { 2 - 4 } & TM & $217-074$ & $27 / 06 / 2000$ \\
\cline { 2 - 4 } & TM & $218-074$ & $18 / 06 / 2000$ \\
\cline { 2 - 4 } & TM & $217-074$ & $12 / 07 / 2011$ \\
\cline { 2 - 4 } & TM & $218-074$ & $17 / 06 / 2011$ \\
\hline
\end{tabular}

\subsection{Pré-Processamento das Imagens Digitais}

$\mathrm{Na}$ etapa de pré-processamento as imagens foram corrigidas geometricamente utilizando o programa ENVI (Environment for Visualizing Images) versão 4.8.

Para a correção geométrica foram utilizadas imagens TM/Landsat 5 Geo Cover como referência. Foram coletados pontos de controle terrestres (PCT) distribuídos espacialmente por toda a imagem de modo que o valor da raiz de erro médio quadrático (RSME) não ultrapassasse meio pixel. Utilizou-se o sistema de equações polinomiais de segundo grau pelo método de reamostragem do valor do pixel vizinho mais próximo (Nearest Neighbor).

Em seguida, realizou-se a correção atmosférica das imagens no mosaico de 1985 aplicando-se o método de Correção Atmosférica pelo Pixel Escuro ou Dark Object Subtraction - DOS, proposto por Chavez (1998).

\subsection{Classificação digital do mosaico de 1985}

Na elaboração do mapa temático de uso e cobertura do solo do QF utilizou-se o mosaico georreferenciado confeccionado com as duas imagens do ano de 1985.

O mapeamento do uso e cobertura do solo foi obtido através da classificação orientada a objetos por meio do programa E-Cognition Developer 8.0 (ECOGNITION, 2009). Para a segmentação do mosaico de 1985 fez-se uso do algoritmo de multi-resolução descrito por Baatz \& Shaäpe (2000) que utiliza de critérios de homogeneidade, além de um parâmetro de escala para assim delimitar os objetos complexos que compõe a paisagem. Dessa forma, foi possível agrupar pixels próximos com atributos similares em regiões ou objetos, fato este que proporcionou maior quantidade de descritores, tais como, forma, tamanho e textura, 
aumentando o número de variáveis de entrada no processo de classificação (BOTELHO \& CENTENO, 2005).

Diversos testes de segmentação foram realizados utilizando-se pesos iguais para todas as bandas do mosaico de 1985, sendo que em cada segmentação, diferentes parâmetros de escala, forma, cor, compacidade e suavidade foram testados e avaliados, levando-se em consideração o tamanho e a forma dos objetos resultantes, de modo que estes fossem compatíveis com os objetivos do mapeamento.

No processo de classificação digital do mosaico de 1985, primeiramente foram coletadas amostras das diferentes classes de cobertura do solo. Em seguida, essas amostras foram aleatoriamente distribuídas em dois conjuntos com números similares de objetos para cada classe de cobertura do solo - um conjunto chamado de amostras de treinamento e outro conjunto chamado de amostras de acurácia. Utilizando o conjunto das amostras de treinamento, aplicou-se o algoritmo do vizinho mais próximo para discriminação das classes de cobertura do solo, com base não somente nas características espectrais das seis bandas de cada objeto, como também de outros atributos, como a média da banda 4, a máxima diferença para as seis bandas e descritores de forma. Ao final, o resultado da classificação foi comparado ao mosaico de 1985, e aqueles polígonos que foram mal classificados foram editados e corrigidos utilizando técnicas de interpretação visual.

Após essa etapa, realizou-se a avaliação da exatidão da classificação, com base nas amostras de acurácia. Para isso calculou-se a matriz de confusão e o coeficiente Kappa, a partir da equação:

$$
\hat{K}=\frac{n \sum_{i=1}^{k} n_{i i}-\sum_{i=1}^{k} n_{i+} n_{+i}}{n^{2}-\sum_{i=1}^{k} n_{i+} n_{+i}}
$$

Em que: $\hat{K}=$ Coeficiente Kappa; $k=$ número de linhas na matriz; $n_{i i}=$ número de observações na linha [i] e coluna $[i] ; n_{i}$ e $n_{+i}=$ totais marginais da linha [i] e coluna $[i]$, respectivamente; e $\mathrm{n}=$ número total de observações.

Segundo Congalton \& Green (2009) a matriz de confusão, quando elaborada corretamente, possui eficiência comprovada e representa de forma explícita a confiabilidade do mapa para os planejadores que o utilizarão na tomada de decisão.

\subsection{Deteç̧ão da Expansão da Mineração e Quantificação da Área de Vegetação Florestal Nativa Suprimida}

Para delimitar as áreas mineradas foram criados polígonos de mineração nos mosaicos das imagens TM/Landsat 5 ao longo de todos os anos avaliados. Os 
polígonos foram identificados por meio da criação de regiões de interesse nas imagens utilizando técnicas de interpretação visual no programa ENVI 4.8. Para melhor delimitação das áreas mineradas, os polígonos foram conferidos e corrigidos através de recursos disponíveis no módulo ArcMap do programa ArcGis 10.1 (ESRI, 2010).

Para identificação e análise da supressão da vegetação florestal nativa pela mineração efetuou-se a sobreposição do mapa temático de cobertura e uso do solo no ano base de 1985 e dos polígonos de mineração nos anos de 1989, 2000 e 2011, utilizando-se os recursos disponíveis no módulo ArcMap do programa ArcGis 10.1 (ESRI, 2010), encontrando-se, assim, as regiões de interseções, correspondentes as áreas de vegetação perdidas pela expansão da mineração, de modo que a área de vegetação florestal nativa suprimida pelas atividades de mineração foi calculada em cada período de anos de análise (1985-1989, 1989-2000 e 2000-2011), tendo como base a área de vegetação florestal nativa existente na classificação do mosaico de 1985.

\section{RESULTADOS}

\subsection{Expansão das Áreas Mineradas no QF}

$\mathrm{Na}$ Tabela 2 encontra-se a área ocupada pela mineração em cada ano de análise.

Tabela 2 - Áreas mineradas em cada ano de análise.

\begin{tabular}{c|c|c}
\hline Ano & Área Minerada (ha) & Expansão (ha) \\
\hline 1985 & 3823,68 & - \\
\hline 1989 & 4759,60 & 935,92 \\
\hline 2000 & 6851,76 & 2092,15 \\
\hline 2011 & 11967,77 & 5116,01 \\
\hline
\end{tabular}

Observa-se que de 1985 a 1989 houve expansão de 935,92 ha, o que corresponde a aumento de $24,48 \%$ na área total minerada no QF. No período de 1989 a 2000 e de 2000 a 2011 houve ampliação da área minerada de 2.092,15 ha e $5.116,01$ ha, respectivamente, correspondendo a aumento de $43,95 \%$ no período de 1989 a 2000 e 74,66\% no período de 2000 a 2011.

Considerando a taxa anual de expansão da mineração, tem-se que no período de 1985 a 1989 houve incremento de 233,98 ha/ano, e de 1989 a 2000 houve incremento de 190,20 ha/ano, e no período de 2000 a 2011 houve incremento de 465,09 ha/ano.

Observa-se nas Figuras 2, 3, 4 e 5 a distribuição espacial das áreas mineradas ao longo dos anos analisados. 
Figura 2 - Áreas Mineradas no Quadrilátero Ferrífero em 1985.

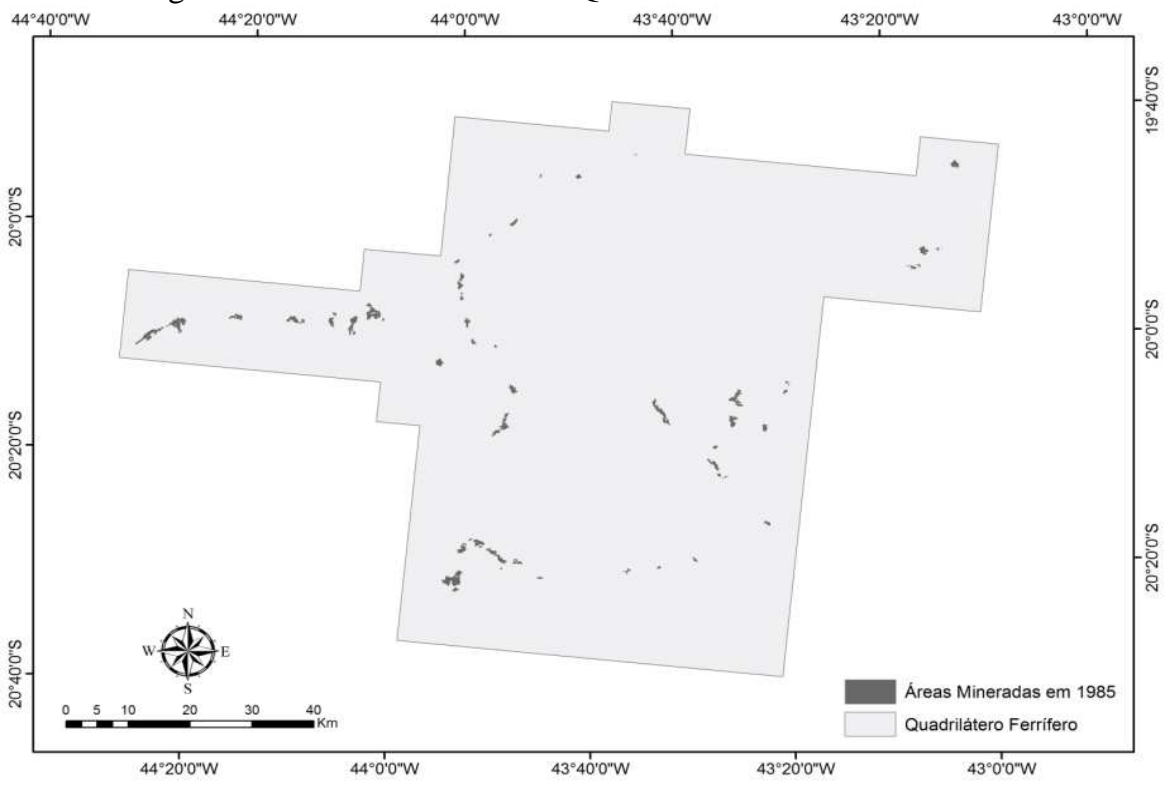

Figura 3 - Áreas Mineradas no Quadrilátero Ferrífero em 1989.

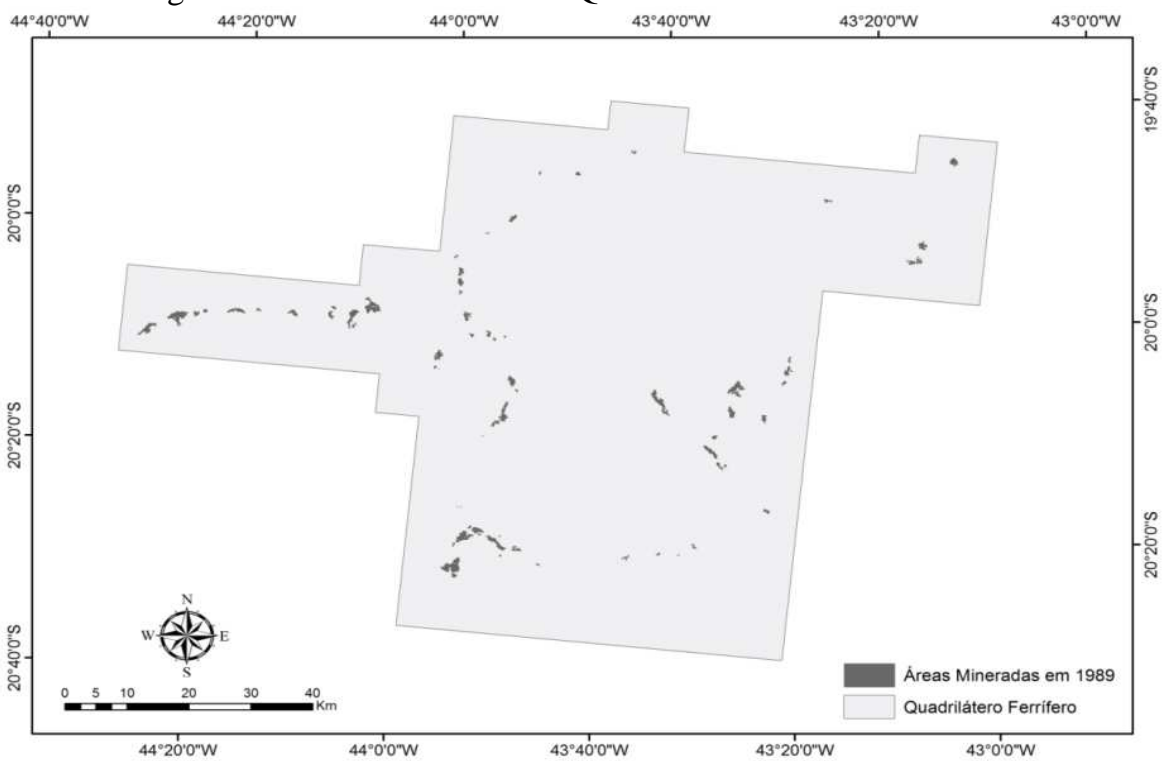

Bol. Ciênc. Geod., sec. Artigos, Curitiba, v. 20, nº 3, p.683-700, jul-set, 2014. 
Figura 4 - Áreas Mineradas no Quadrilátero Ferrífero em 2000.

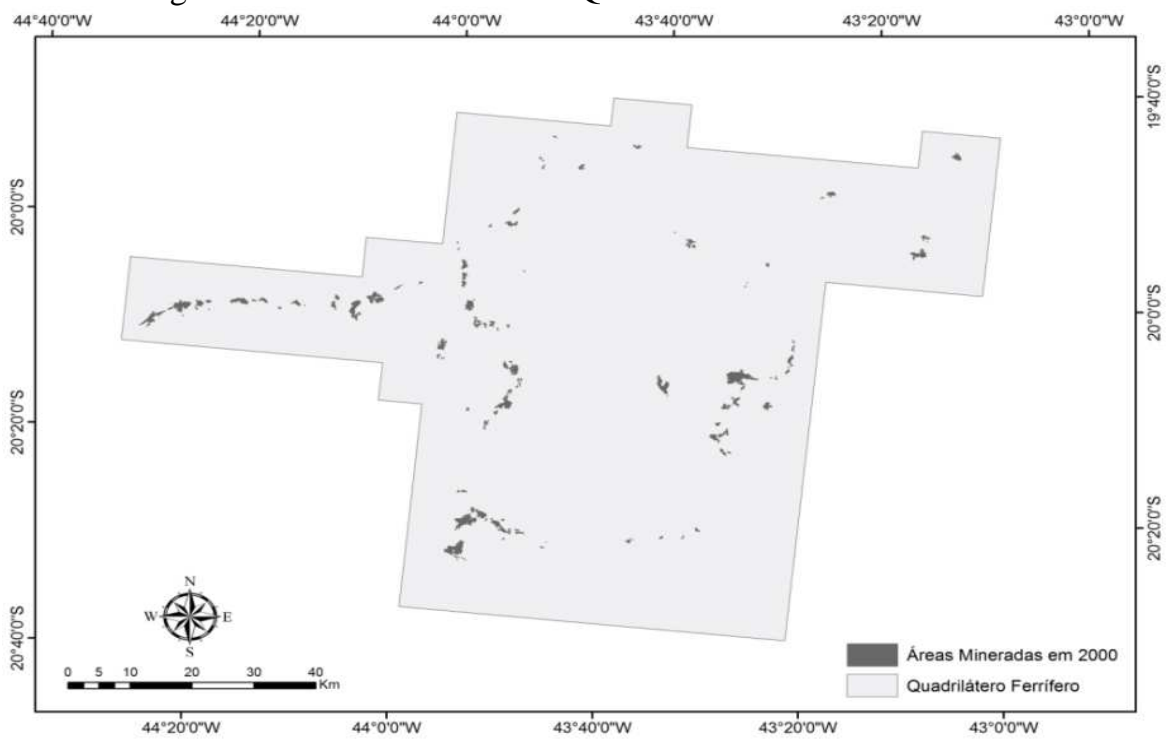

Figura 5 - Áreas Mineradas no Quadrilátero Ferrífero em 2011.

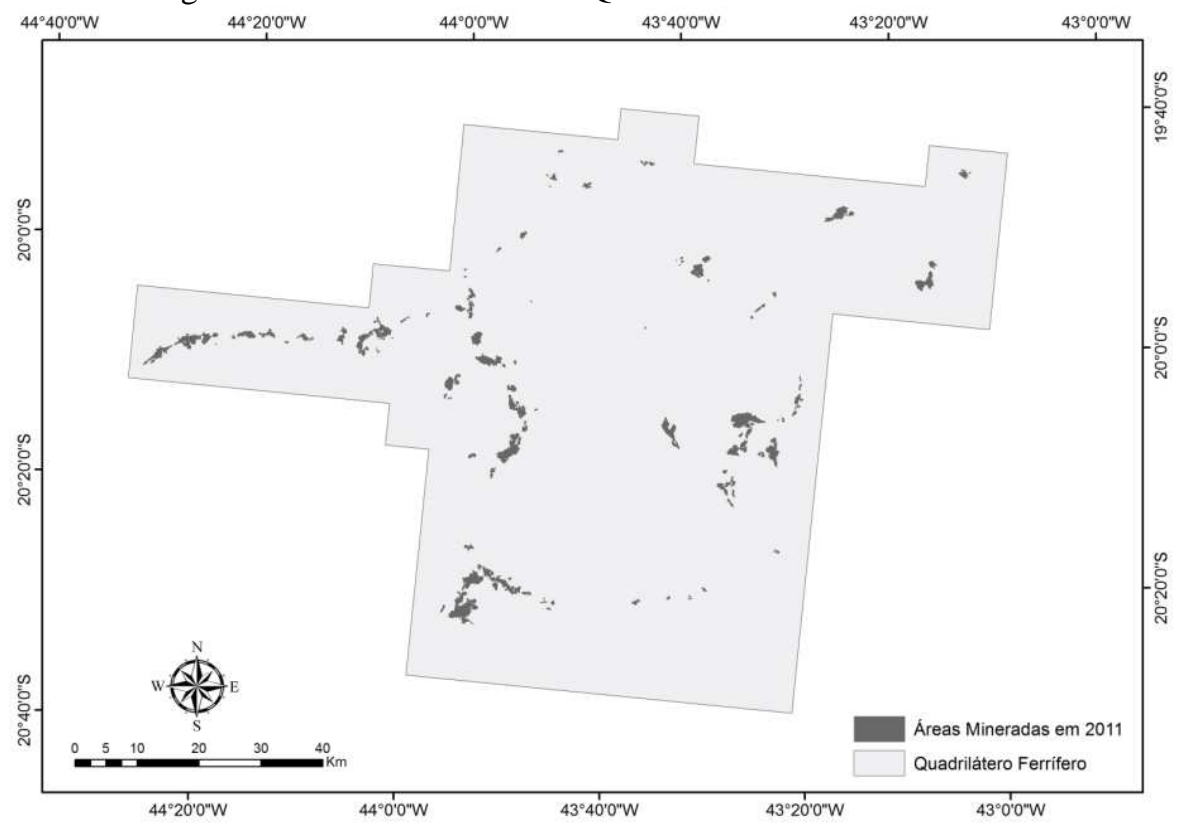

Bol. Ciênc. Geod., sec. Artigos, Curitiba, v. 20, nº 3, p.683-700, jul-set, 2014. 
Historicamente, tem-se que no período de 1978 a 1997, o PIB industrial brasileiro apresentou crescimento médio de apenas $1,96 \%$, passando por uma etapa onde a economia encontrava-se desestabilizada com a privatização de grandes empresas. Após a estabilização econômica, houve expansão do consumo de alguns bens primários, entre eles o minério de ferro. $\mathrm{O}$ minério de ferro apresentou variação anual do consumo de 5,71\% (BRASIL, 2000).

Neste mesmo período ocorreu aumento nas exportações brasileiras de ferro, que foram subsidiadas pelo crescimento da demanda mundial de aço, pela expansão da produção de aço distante das fontes de minério e pela competitividade brasileira desta mineração em âmbito mundial (BRASIL, 2000).

Em 2000, o Brasil foi considerado o maior produtor de minério de ferro beneficiado, e se forem consideradas também suas reservas inferidas, totaliza-se uma produção de 54 bilhões de toneladas. Neste ano o país era detentor de $6,5 \%$ das reservas mundiais de minério de ferro, correspondendo a 19,2 bilhões de toneladas dos 300 bilhões de toneladas que totalizavam a reserva mundial deste minério. Destas reservas, 72,2\% eram encontradas no Estado de Minas Gerais (ANUÁRIO..., 2001).

O consumo de minério de ferro no Brasil está concentrado basicamente nas usinas siderúrgicas integradas e nos produtores independentes de minério de ferro, sendo este quase exclusivamente destinado à produção de ferro gusa e esponja que serão transformados em aço e destinados para a produção de pelotas (ANUÁRIO..., 2001).

O histórico de produção de minério no Brasil, e principalmente no estado de Minas Gerais corroboram com os resultados obtidos neste estudo, pois o aumento da produção de minério consequentemente acarretou expansão das áreas mineradas no estado. No período de 1985 a 2000, houve expansão de 3.028,07 ha, que correspondem a aumento de 79,19\% na área ocupada pela mineração no QF.

Em 2010 a economia brasileira teve o mais elevado crescimento do PIB dos últimos 25 anos, crescendo 7,5\% com um total de R\$3,7 trilhões, o que foi proporcionado pelas fortes demandas internas, que ocorreram principalmente nos países emergentes (DNPM, 2012). Neste ano, as exportações nacionais somaram US\$ 201,9 bilhões, com a exportação do minério de ferro igual a US\$28,9 bilhões, sendo considerado o líder dos produtos exportados e com uma receita duas vezes maior que no ano anterior (DNPM, 2012).

As reservas brasileiras totalizaram em 2010, 20,4 bilhões de toneladas do minério de ferro, sendo que as reservas mundiais corresponderam a 180 bilhões de toneladas. As reservas brasileiras de minério de ferro estão distribuídas principalmente nos estados de Minas Gerais, Pará e Mato Grosso do Sul. Neste ano, o Brasil foi o terceiro maior produtor de ferro do mundo, com $15,5 \%$ da produção mundial, tendo Minas Gerais como o principal estado produtor, responsável por 69,9\% desta produção (DNPM, 2012).

Analisando o aumento da área minerada entre 2000 e 2011, nota-se aumento expressivo de 74,66\%. Entre os anos de 1985 a 2011, é observado aumento de $213 \%$

Bol. Ciênc. Geod., sec. Artigos, Curitiba, v. 20, nº 3, p.683-700, jul-set, 2014. 
na área minerada no QF, correspondentes a 8.144,09 ha. Esse aumento pode ser relacionado ao grande crescimento das exportações, do PIB nacional, e pelas fortes demandas internas pelo produto neste período de anos. De um modo geral, a expansão das áreas mineradas no QF está diretamente relacionada com a expansão econômica brasileira.

Uma análise realizada entre 1980 e 2005 sobre a evolução das reservas de minérios indicou aumento nacional de $115 \%$, enquanto que o crescimento mineiro foi igual a $52,7 \%$, tendo como os principais municípios detentores dessas reservas os municípios pertencentes ao Quadrilátero Ferrífero: Barão de Cocais (1.468 milhões de toneladas de reserva medida, indicada e inferida); Itabira (1.942 milhões de toneladas); Itabirito (860 milhões de toneladas); Mariana (17.434 milhões de toneladas); Nova Lima (2.275 milhões de toneladas); Ouro Preto (9.980 milhões de toneladas); Santa Bárbara (2.504 milhões de toneladas), corroborando com os resultados encontrados neste estudo, que apresentam grande crescimento na área minerada nos municípios pertencentes ao Quadrilátero Ferrífero, entre os anos de 1985 a 2011 (Tabela 3). Minas Gerais contempla 9,5 bilhões de toneladas das reservas lavráveis (MME, 2009).

$\mathrm{Na}$ Tabela 3 encontra-se a área minerada por município em cada ano de análise.

Tabela 3 - Área minerada por município em cada ano de análise.

\begin{tabular}{c|c|c|c|c}
\hline \multirow{2}{*}{ Municípios } & \multicolumn{4}{|c}{ Área minerada (ha) } \\
\cline { 2 - 5 } & $\mathbf{1 9 8 5}$ & $\mathbf{1 9 8 9}$ & $\mathbf{2 0 0 0}$ & $\mathbf{2 0 1 1}$ \\
\hline Barão de Cocais & - & - & 99,41 & 367,49 \\
\hline Bela Vista de Minas & 79,24 & 84,47 & 87,24 & 96,55 \\
\hline Belo Horizonte & 71,79 & 71,13 & 69,25 & 95,75 \\
\hline Belo Vale & 12,3 & 20,28 & 65,64 & 181,45 \\
\hline Brumadinho & 597 & 657 & 818,3 & 1144,2 \\
\hline Caeté & 1,2 & 4,57 & 7,41 & 29,16 \\
\hline Catas Altas & 12,92 & 96,54 & 111,8 & 135,5 \\
\hline Congonhas & 464,4 & 581,8 & 653,8 & $1.199,5$ \\
\hline Ibirité & - & - & 17,67 & 19,87 \\
\hline Igarapé & 3,87 & 10,44 & 74,68 & 100,09 \\
\hline Itabira & 0,31 & 0,6 & 1,82 & 10,05 \\
\hline Itabirito & 236,7 & 282,2 & 450,2 & 995,79 \\
\hline Itatiaiuçu & 378 & 432,3 & 489,4 & 703,1 \\
\hline Itaúna & 32,5 & 26,79 & 49,04 & 60,74 \\
\hline João Monlevade & 7,48 & 14,1 & 5,96 & 7,92 \\
\hline
\end{tabular}




\begin{tabular}{c|c|c|c|c}
\hline Mariana & 371,4 & 454,1 & 835,6 & 1485,3 \\
\hline Mário Campos & 0,06 & 1,6 & 21,06 & 27,57 \\
\hline Mateus Leme & 48,56 & 93,26 & 157,2 & 209,08 \\
\hline Nova Lima & 272,4 & 370,1 & 750,5 & $1.499,6$ \\
\hline Ouro Preto & 660,6 & 832,2 & 1014 & $1.617,9$ \\
\hline Rio Acima & 63,91 & 81,27 & 109,9 & 124,38 \\
\hline Rio Piracicaba & 113,6 & 101,3 & 66,15 & 143,85 \\
\hline Sabará & 45,84 & 57,07 & 118 & 211,99 \\
\hline Santa Bárbara & 140,3 & 246,4 & 464,9 & 724,6 \\
\hline Santa Luzia & - & - & 11,97 & 21,1 \\
\hline São Gonçalo do Rio Abaixo & - & 29,97 & 79,47 & 405,27 \\
\hline São Joaquim de Bicas & 37,07 & 22,64 & 42,34 & 57,31 \\
\hline Sarzedo & 172,3 & 188 & 179,7 & 292,63 \\
\hline
\end{tabular}

Observando a Tabela 3 é possível inferir que os municípios que apresentaram a maior área minerada em 2011 correspondem às cidades históricas de Ouro Preto, com 1.617,90 ha minerados, Nova Lima com 1.499,59 ha minerados e Mariana, com $1.485,34$ ha minerados.

Nota-se também que houve a inserção de alguns municípios ao longo dos anos. Em 1989, São Gonçalo do Rio Abaixo passou a ter uma área minerada de 29,97 ha. No ano 2000, Barão de Cocais, Ibirité e Santa Luzia passaram a apresentar área minerada de 99,41 ha, 17,67 ha e 11,97 ha, respectivamente.

\subsection{Classificação Digital do Mosaico de 1985}

Os parâmetros de escala, forma e cor, utilizados para a segmentação do mosaico de 1985 foram respectivamente iguais a 20,0,3 e 0,7. O fator de suavidade foi igual a 0,7 e o fator de compacidade igual a 0,3 .

Foram mapeadas as seguintes classes de cobertura e uso do solo: mineração, vegetação nativa, cidade, pastagem, campo, água e solo exposto (Figura 6).

Os valores de Exatidão Global e do coeficiente Kappa foram respectivamente iguais a 97,44\% e 96,89\%. Segundo Congalton \& Green (2009) valores de coeficiente Kappa entre $80 \%$ e $100 \%$ são considerados excelentes e indicam que a classificação alcançou um resultado satisfatório. Estes coeficientes são uma estatística que indica o grau de concordância entre o resultado da classificação digital e a realidade no campo. 
Figura 6 - Mapa de uso e ocupação do solo solo do QF em $\underbrace{}_{434000007} 1985$.

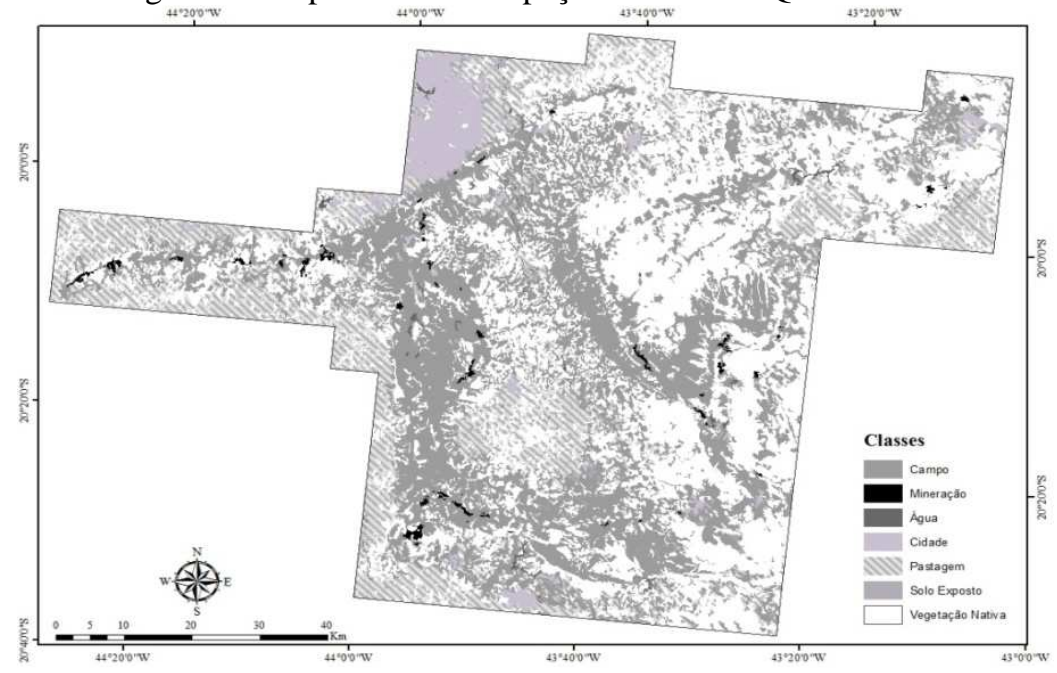

\section{3 Área de Vegetação Florestal Nativa Suprimida}

Na Tabela 4 encontra-se a área de vegetação florestal nativa suprimida pelo avanço da mineração em cada período de análise.

Tabela 4 - Vegetação florestal nativa suprimida pela mineração em cada período de análise.

\begin{tabular}{c|c}
\hline Período & Vegetação florestal Suprimida (ha) \\
\hline $1985-1989$ & 324,42 \\
\hline $1989-2000$ & 948,98 \\
\hline $2000-2011$ & 1989,69 \\
\hline Total & 3263,09 \\
\hline
\end{tabular}

Observa-se na Tabela 4 que os aumentos nas perdas de vegetação florestal existentes entre os períodos de 1985-1989, 1989-2000 e 2000-2011 correspondem, respectivamente, a $9,94 \%, 29,08 \%$ e $60,97 \%$. Nota-se que a maior perda vegetal ocorreu entre os anos de 2000 a 2011, período correspondente com a maior produção de minério pelo Estado de Minas Gerais (DNPM, 2012).

A área de vegetação florestal suprimida pela mineração por município em cada período de análise encontra-se na Tabela 5. Observa-se que nos anos de 1985 a 1989, houve uma maior perda de vegetação florestal nativa nos municípios de Itatiaiuçu, 47,28 ha, Santa Barbara, 46,19 ha, Brumadinho, 37,89 ha e Ouro Preto, 32,52 ha. As áreas de vegetação florestal nativa perdidas somente nesses quatro municípios correspondem a 50,52\% de todo desflorestamento ocasionado pelo avanço da mineração no QF. 
No período entre 1989 a 2000, os municípios de Santa Bárbara, Mariana e Ouro Preto, apresentaram uma grande perda vegetal devido ao avanço da atividade mineradora, correspondente à $13,80 \%, 12,17 \%$ e $11,85 \%$, respectivamente, de todo o desflorestamento ocasionado pelo avanço da mineração no QF neste período de anos. Analisando o período de anos de 2000 a 2011 houve uma maior perda vegetal nos municípios de Mariana (396,49 ha), São Gonçalo do Rio Abaixo (302,77 ha), Barão de Cocais (236,56 ha) e Santa Bárbara (205,58 ha), correspondendo a 57,37\% de toda a vegetação florestal perdida pelo avanço da mineração no $\mathrm{QF}$.

Tabela 5 - Vegetação florestal nativa suprimida pela mineração por município em cada período de análise.

\begin{tabular}{|c|c|c|c|}
\hline \multirow{2}{*}{ Municípios } & \multicolumn{3}{|c|}{ Vegetação Florestal Suprimida (ha) } \\
\hline & $1985-1989$ & $1989-2000$ & $2000-2011$ \\
\hline Barão de Cocais & - & 82,96 & 236,56 \\
\hline Bela Vista de Minas & 6,28 & 7,49 & 8,88 \\
\hline Belo Vale & - & 8,68 & 20,09 \\
\hline Brumadinho & 37,89 & 97,79 & 90,88 \\
\hline Caeté & - & 3,97 & 21,26 \\
\hline Catas Altas & 7,10 & 1,19 & 5,38 \\
\hline Congonhas & 20,46 & 48,68 & 113,49 \\
\hline Ibirité & - & 2,10 & 3,10 \\
\hline Igarapé & - & 12,14 & 10,35 \\
\hline Itabira & 1,94 & 2,98 & 9,14 \\
\hline Itabirito & 2,45 & 19,17 & 90,05 \\
\hline Itatiaiuçu & 47,28 & 50,02 & 90,00 \\
\hline Itaúna & 5,79 & 11,42 & 5,82 \\
\hline João Monlevade & 7,71 & 0,86 & 1,75 \\
\hline Mariana & 29,50 & 115,52 & 396,49 \\
\hline Mário Campos & - & 10,58 & 4,69 \\
\hline Mateus Leme & 18,39 & 41,97 & 23,17 \\
\hline Nova Lima & 8,31 & 91,93 & 81,42 \\
\hline Ouro Preto & 32,52 & 112,53 & 140,32 \\
\hline Rio Acima & - & - & 0,58 \\
\hline Rio Piracicaba & 15,28 & 20,02 & 57,11 \\
\hline Sabará & 0,65 & 11,74 & 23,92 \\
\hline Santa Bárbara & 46,19 & 131,01 & 205,58 \\
\hline Santa Luzia & - & 6,43 & 9,86 \\
\hline São Gonçalo do Rio Abaixo & 25,04 & 41,01 & 302,77 \\
\hline São Joaquim de Bicas & 1,09 & 4,15 & 6,30 \\
\hline Sarzedo & 10,53 & 12,63 & 30,73 \\
\hline
\end{tabular}

Bol. Ciênc. Geod., sec. Artigos, Curitiba, v. 20, nº 3, p.683-700, jul-set, 2014. 
Entre os municípios que iniciaram a mineração após o ano de 1985 (Tabela 3) nota-se que a exploração minerária no município de São Gonçalo do Rio Abaixo teve início no ano de 1989, com uma área de 29,97 ha, sendo que $83,55 \%$ desta área era anteriormente coberta por vegetação nativa. Nos municípios que tiveram áreas de mineração detectadas pela primeira vez no ano 2000, Barão de Cocais, Santa Luzia e Ibirité, percebeu-se que as áreas de vegetação florestal nativa perdidas correspondem a $83,45 \%, 53,69 \%$ e $11,89 \%$, respectivamente, da área total minerada nesses municípios. Portanto, o maior avanço minerário nesses municípios ocorreu em áreas anteriormente cobertas por vegetação nativa.

Uma análise realizada em 2000 sobre o desenvolvimento do setor mineral estimou demanda para os próximos anos dos minerais produzidos no país (BRASIL, 2000). Junto com o potássio, o ferro representou um dos dois bens de maior necessidade de investimento até 2010, que ficou estimado em US\$ 3,1 bilhões, sendo US\$ 1,8 bilhão para atender à expansão da demanda interna e US\$1,3 bilhão para atender ao crescimento esperado das exportações. Em 2010 a demanda projetada para o mercado interno foi de 136,8 milhões de toneladas de minério, relacionadas à demanda nacional e às exportações de aço, ferro gusa e pelotas (BRASIL, 2000).

Com a crescente demanda por minerais pode-se esperar maior perda vegetal para os próximos anos, em decorrência do aumento das áreas mineradas e surgimento de novas minas. $\mathrm{O}$ aumento da produtividade e dos investimentos em pesquisa, e a ampliação da área minerada, impacta de forma direta a vegetação localizada nas principais áreas possíveis de mineração.

É importante ressaltar que os resultados encontrados nesse estudo são dependentes das imagens utilizadas e da metodologia adotada, podendo diferir de outros estudos que adotem outra metodologia ou outra base de dados como referência.

\section{CONCLUSÕES}

Em função da grande quantidade de minério de ferro comercializada no Brasil nas últimas décadas houve grande aumento das áreas exploradas pela mineração no Quadrilátero Ferrífero.

O maior aumento da área minerada foi constatado entre os anos de 2000 a 2011, o que ressalta a relação entre o aumento de produtividade e a sua comercialização.

$\mathrm{O}$ avanço na mineração impactou drasticamente a cobertura vegetal, de modo que uma grande área anteriormente coberta por vegetação florestal nativa foi suprimida. Os resultados desse estudo podem também fornecer subsídios para programas de compensação de impactos ambientais e recuperação de áreas degradadas causadas pela expansão da mineração, uma vez que este estudo constatou não somente as áreas de vegetação florestal nativa suprimidas, bem como onde, ou seja, em quais municípios essa supressão causou o maior impacto ambiental. 


\section{REFERÊNCIAS BIBLIOGRÁFICAS}

ANUÁRIO MINERAL BRASILEIRO. Brasília, Departamento Nacional de Produção Mineral. 2001.159 p.

BAATZ, M.; SCHÄPE, A. Multiresolution segmentation: an optimization approach for high quality multi-scale image segmentation. In: ANGEWANDTE GEOGRAPHISCHE INFORMATIONS VERARBEITUNG, 12, 2000, Heibelberg. Proceedings... Heidelberg: Wichmann-Verlag, 2000.

BERTANI, T. C. Sensoriamento remoto aplicado ao mapeamento de paleomorfologias no interflúvio Madeira-Purus, Sudoeste da Amazônia Brasileira. 129 f. Dissertação (Mestrado em Sensoriamento Remoto), Instituto Nacional de Pesquisas Espaciais, São José dos Campos, 2011.

BOTELHO, M. F.; CENTENO, J. A. S. Uso integrado de imagem de alta resolução espacial e altura derivada do laser scanner na escolha do classificador orientado a região. Boletim de Ciências Geodésicas, Curitiba, v. 11, n. 1, p. 7187, jan./jun. 2005.

BRANDÃO, M.; GAVILANES, M. L.; BUENDIA, J. P. L.; J.F. MACEDO, J. F.; CUNHA, L. H. S. Contribuição para o conhecimento da cadeia do espinhaço em Minas Gerais (Serra de Itabirito). Daphne, n. 1, p. 39-41, 1991.

BRASIL Secretaria de Minas e Metalurgia. Mineração no Brasil: previsão de demanda e necessidade de investimentos. Secretaria de Minas e Metalurgia Brasília. 2000. 50 p.

CARMO, F.F. Importância Ambiental e Estado de Conservação dos Ecossistemas de Cangas no Quadrilátero Ferrífero e Proposta de Áreas-Alvo para a Investigação e Proteção da Biodiversidade em Minas Gerais. Dissertação (Pós-graduação em Ecologia, Conservação e Manejo da Vida Silvestre), 98f. Universidade Federal de Minas Gerais, Belo Horizonte, 2010.

CHAVEZ JR., P.S. An improved dark-object subtraction technique for atmospheric scattering correction of multispectral data. Remote Sensing of Environment, New York, v.24, p. 459-479, 1988.

CONGALTON, R. G., GREEN, K. Assessing the Accuracy of Remotely Sensed Data: Principles and Practices. $2^{\circ}$ Ed. CRC/Taylor \& Francis, Boca Raton, 2009. 183p.

DNPM (Departamento Nacional de Produção Mineral). Sumário Mineral 2011. Brasília, DNPN, 2012.

DNPM (Departamento Nacional de Produção Mineral). Sumário Mineral 2009. Brasília, DNPN, 2010. 128 p.

DRUMMOND, G. M.; MARTINS, C. S.; MACHADO, A. B. M.; SEBAIO, F. A.; ANTONINI, Y. Biodiversidade em Minas Gerais: Um Atlas para sua Conservação. Belo Horizonte: Fundação Biodiversitas, 2005, 222 p.

ECOGNITION. Userguide 8. Definiens Imaging. Müchen, Germany, 2009. 236 p. ENVIRONMENTAL SYSTEMS RESEARCH INSTITUTE ArcGIS Desktop: Release 10.1. Redlands, CA: ESRI, 2010. 
FARIAS, C. E. G. Mineração e meio ambiente no Brasil. Relatório CGEE. 40 p., 2002.

GARCIA, L. C. Fenologia de espécies da canga em Barão de Cocais, Quadrilátero Ferrífero de Minas Gerais. Dissertação (Mestrado em Ecologia, Conservação e Manejo da Vida Silvestre), 123f. Universidade Federal de Minas Gerais, Belo Horizonte, 2007.

JACOBI, C.M.; CARMO, F.F.; VINCENT, R.C.; STEHMANN, J. R. Plant communities on ironstone outcrops - a diverse and endangered Brazilian ecosystem. Biodiversity and Conservation,v.16, p. 2185-2200, 2007.

JACOBI, C. M., CARMO, F. F. Diversidade dos campos rupestres ferruginosos no Quadrilátero Ferrífero, MG. Megadiversidade, v. 4, p. 9, 2008.

JENSEN, J. R. Introductory digital image processing. Englewood Cliffs: Prentice Hall, 1986. $51 \mathrm{p}$.

LAMOUNIER, W. L.; CARVALHO, V. L. M.; SALGADO, A. A. R. Serra do Gandarela: Possibilidade de ampliação das Unidades de Conservação no Quadrilátero Ferrífero-MG. Revista do Departamento de Geografia, v. 22, p. 171-192, 2011.

MATHER, P. M. Computer processing of remotely-sensed images: an introduction. London: Wiley, 2004. 324 p.

MEYER, S. T.; SILVA, A. F.; MARCO JR, P.; MEIRA NETO, J. A. A. Composição florística da vegetação arbórea de um trecho de floresta de galeria do Parque Estadual do Rola-Moça na Região Metropolitana de Belo Horizonte, MG, Brasil. Acta Botanica Brasilica, São Paulo, v. 18, n. 4, p. 701-709, 2004.

MINISTÉRIO DE MINAS E ENERGIA (MME). Perfil da Mineração de Ferro. Secretaria de Geologia, Mineração e Transformação Mineral-SGM, 2009.

PIACENTINI, T.; BOGGIANI, P.C.; YAMAMOTO, J.K.; FREITAS, B.T. \& CAMPANHA, G.A.C.C. 2007. Formação ferrífera associada à sedimentação glaciogênica da Formação Puga (Marinoano) na Serra da Bodoquena, MS. Revista Brasileira de Geocências, v. 37, n. 3, p. 530-541, 2007.

ROESER, H. M. P.; ROESER, P. A. O Quadrilátero Ferrífero - MG, Brasil: aspectos sobre sua história, seus recursos minerais e problemas ambientais relacionados. Geonomos, v. 18, n. 1, p. 33 - 37, 2010.

RUCHKYS, U. A. Geoparques e a Musealização do Território: um Estudo Sobre o Quadrilátero Ferrífero. Geologia, São Paulo, v. 5, p. 35-46, 2009.

SPÓSITO, T. C.; STEHMANN, J. R. Heterogeneidade florística e estrutural de remanescentes florestais da Área de Proteção Ambiental ao Sul da Região Metropilitana de Belo Horizonte (APA Sul-RMBH), Minas Gerais, Brasil. Acta Botanica Brasilica, São Paulo, v. 20, n. 2, p. 347-362, 2006.

VAREJÃO, C. A. C.; SALGADO, A. A. R.; VARAJÃO, A. F. D. C.; BRAUCHER, R.; COLIN, F.; NALINI JÚNIOR, H. A. Estudo da evolução da paisagem do Quadrilátero Ferrífiero (Minas Gerais, Brasil) por meio da mensuração das taxas de erosão ( $\left.{ }^{10} \mathrm{be}\right)$ e da pedogênese. Revista Brasileira de Ciência do Solo, v.33, p.1409-1425, 2009. 
VIANA, P. L.; LOMBARDI, J. A. Florística e caracterização dos campos rupestres sobre canga na Serra da Calçada, Minas Gerais, Brasil. Rodriguésia, Rio de Janeiro, v. 58, n. 1, p. 159-177, 2007.

VINCENT, R.C.; JACOBI, C.; ANTONINI, Y. Diversidade na adversidade. Ciência Hoje, v.31, p. 64-67, 2002

VICENT, R. C.; MEGURO, M. Influence of soil properties on the abundance of plant species in ferruginous rocky soils vegetation, southeastern Brazil. Revista Brasileira Botânica, v.31, n.3, p.377-388, jul-set. 2008.

(Recebido em fevereiro de 2014. Aceito em junho de 2014). 